From the Pediatric Hematology/Oncology, University of California at San Francisco Children's Hospital, San Francisco; Pediatric Hematology/Oncology, University of California at Los Angeles David Geffen School of Medicine, Los Angeles, CA; Public Health Sciences, University of Alberta, Edmonton, $A B$; Pediatric Hematology/Oncology, Hospital for Sick Children, Toronto, ON, Canada; Pediatric Hematology/Oncology, University of Texas Southwestern Medical Center, Dallas, TX; Epidemiology and Cancer Control, St. Jude Children's Research Hospital, Memphis, TN; Neurology, Children's National Medical Center, Washington, DC.

Submitted March 6, 2009; accepted August 10, 2009; published online ahead of print at www.jco.org on November 16, 2009

Supported by Grant No. U24 CA55727 from the National Cancer Institute (L.L.R.); by the American Lebanese Syrian Associated Charities (St. Jude Children's Research Hospital); and in part by funds from the Campini Foundation, Mount Zion Foundation, and Swim Across America.

Authors' disclosures of potential conflicts of interest and author contributions are found at the end of this article.

Corresponding author: Robert Goldsby MD, UCSF Pediatric Oncology, 505

Parnassus Ave, Box 0106, San Francisco, CA 94143-0106; e-mail: goldsbyr@peds.ucsf.edu.

(C) 2009 by American Society of Clinical Oncology

$0732-183 \times / 10 / 2802-324 / \$ 20.00$

DOI: $10.1200 / J C O .2009 .22 .5060$

\title{
Late-Occurring Neurologic Sequelae in Adult Survivors of Childhood Acute Lymphoblastic Leukemia: A Report From the Childhood Cancer Survivor Study
}

Robert E. Goldsby, Qi Liu, Paul C. Nathan, Daniel C. Bowers, Amanda Yeaton-Massey, Shannon H. Raber, Daniel Hill, Gregory T. Armstrong, Yutaka Yasui, Lonnie Zeltzer, Leslie L. Robison, and Roger J. Packer

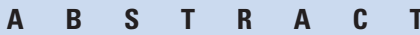

\section{Purpose}

Children with acute lymphoblastic leukemia (ALL) are often cured, but the therapies they receive may be neurotoxic. Little is known about the incidence and severity of late-occurring neurologic sequelae in ALL survivors. Data were analyzed to determine the incidence of adverse long-term neurologic outcomes and treatment-related risk factors.

\section{Patients and Methods}

We analyzed adverse neurologic outcomes that occurred after diagnosis in 4,151 adult survivors of childhood ALL who participated in the Childhood Cancer Survivor Study (CCSS), a retrospective cohort of 5-year survivors of childhood cancer diagnosed between 1970 and 1986. A randomly selected cohort of the survivors' siblings served as a comparison group. Self-reported auditoryvestibular-visual sensory deficits, focal neurologic dysfunction, seizures, and serious headaches were assessed.

\section{Results}

The median age at outcome assessment was 20.2 years for survivors. The median follow-up time to death or last survey since ALL diagnosis was 14.1 years. Of the survivors, 64.5\% received cranial radiation and $94 \%$ received intrathecal chemotherapy. Compared with the sibling cohort, survivors were at elevated risk for late-onset auditory-vestibular-visual sensory deficits (rate ratio [RR], 1.8; $95 \% \mathrm{Cl}, 1.5$ to 2.2), coordination problems ( $\mathrm{RR}, 4.1 ; 95 \% \mathrm{Cl}, 3.1$ to 5.3 ), motor problems $(R R, 5.0 ; 95 \% \mathrm{Cl}, 3.8$ to 6.7$)$, seizures ( $R R, 4.6 ; 95 \% \mathrm{Cl}, 3.4$ to 6.2$)$, and headaches (RR, 1.6; 95\% $\mathrm{Cl}, 1.4$ to 1.7). In multivariable analysis, relapse was the most influential factor that increased risk of late neurologic complications.

\section{Conclusion}

Children treated with regimens that include cranial radiation for ALL and those who suffer a relapse are at increased risk for late-onset neurologic sequelae.

\section{J Clin Oncol 28:324-331. (c) 2009 by American Society of Clinical Oncology}

\section{INTRODUCTION}

Acute lymphoblastic leukemia (ALL) is the most common childhood cancer. Current 5-year survival rates exceed $80 \%{ }^{1}$ Significant advancements that improved survival occurred with the implementation of CNS-directed therapy. ${ }^{2}$ Initially, cranial radiation was the mainstay of CNS-directed therapy, but this was associated with cognitive impairment., Subsequently, most prophylactic treatment regimens substituted intensified intrathecal and systemic chemotherapy for cranial radiation. Radiation is still used in populations at high risk for CNS disease. Acute neurotoxicity has been reported in $8 \%$ to $18 \%$ of children with ALL $^{5-8}$ and occurs as a consequence of CNS leukemia, therapy-related damage, infection, or stroke. CNS-directed therapy can result in leukoencephalopathy, seizures, altered intellectual or psychomotor function, and neurosensory dysfunction..$^{9-12}$ The risk of late neurologic complications related to CNS-directed therapies has not been well established. Several factors may influence risk, including age at the time of treatment, sex, CNS involvementat diagnosis, radiation dose, chemotherapy used, and time from therapy. 3,13-19

The goals of this analysis were to describe the incidence of adverse neurologic conditions occurring at least 5 years after diagnosis and to evaluate the effect of different treatment regimens on the risk of developing these neurologic events. The Childhood Cancer Survivor Study (CCSS) includes data on more than 4,000 survivors of childhood ALL, which 
affords the opportunity to evaluate the long-term neurologic effects of childhood ALL.

\section{PATIENTS AND METHODS}

\section{Inclusion Criteria}

The CCSS is a retrospective cohort of survivors of childhood leukemias, brain tumors, lymphomas, Wilms tumor, neuroblastoma, sarcomas, and bone tumors diagnosed between 1970 and 1986 at one of 26 collaborating institutions (Appendix Table A1, online only). ${ }^{20}$ Patients were eligible for the CCSS if they were younger than 21 years at diagnosis and had survived at least 5 years from diagnosis, independent of disease status.

Approval for the study was obtained from the human subjects committee at each collaborating institution. Consent was obtained from patients (or their proxy) to participate in the study and to allow abstraction of medical records. Additionally, the study recruited the nearest-age sibling of a random sample of participating patients to serve as a comparison group.

Collaborating institutions identified 20,691 5-year survivors who met eligibility criteria. Of these, 14,363 completed a questionnaire or telephone interview, 3,205 declined to participate, 3,058 were lost to follow-up, and 65 were unable to participate because of a language barrier. We previously compared demographic and cancer-related characteristics among participants, nonparticipants, and those lost to follow-up and found that these three groups were similar and not a likely source for bias. ${ }^{21,22}$ There were 4,151 childhood ALL survivors. A group of 3,899 randomly selected siblings of childhood cancer survivors participated and served as the comparison group in this analysis.

\section{Data Collection}

At the time of enrollment, a comprehensive baseline questionnaire was completed by the participant (if age 18 years or older) or his/her parent (if $<$ age 18 years). Surveys were distributed by mail or administered by phone with trained interviewers. The majority of questionnaires were collected between 1994 and 1996. Survey questions regarding neurologic conditions began with the phrase, "Have you ever been told by a doctor or other health care professional that you have or have had... ?" If a participant gave a "yes" response, they were then asked their age at first diagnosis.

Treatment information was abstracted from medical records at the participating institutions. Information on cancer therapy included initial therapy, treatment for any relapse, and any conditioning regimen for bone marrow transplant (BMT). Data regarding exposure to 42 chemotherapeutic agents (either "yes" or "no") were abstracted, and cumulative doses were calculated for selected agents. Surgeries performed for cancer treatment at any time from the date of diagnosis onward, site of any tumor(s), and fields and doses of radiation therapy were recorded. Radiation data were centrally reviewed at the Radiation Physics Center at M. D. Anderson Cancer Center. The baseline questionnaire and abstraction form are available at www.stjude.org/ccss.

Four types of neurologic outcomes were considered: auditoryvestibular-visual sensory deficits, focal neurologic dysfunction, seizure disorder, and headaches. Auditory-vestibular-visual sensory deficits included any hearing loss (defined as hearing loss requiring a hearing aid, deafness in one or both ears not corrected by a hearing aid, or complete deafness in either ear), tinnitus, persistent dizziness, legal blindness in one or both eyes, and double vision. Focal neurologic dysfunction included deficits related to balance, tremors or movement, weakness, or inability to move arm(s) or leg(s). An aggregate variable for "any coordination problem" was derived from balance problems or tremors. Similarly, a variable for "any motor problem" was derived from weakness or inability to move arms(s) or leg(s). Reported decreased sense of touch or feeling was included as focal dysfunction, along with pain or abnormal sensation. A seizure disorder was defined by a report of epilepsy, repeated seizures, convulsions, or blackouts. Headaches were defined as any report of serious headaches or migraines. A "yes" response to any component of an aggregated variable was considered a "yes" for that variable.

\section{Statistical Analysis}

Descriptive analyses of demographics and treatment characteristics of the 5-year ALL survivors were performed. Incidence rates of each neurologic outcome following the 5-year survival were estimated by dividing the observed count of the outcome (only first events were counted for the composite-event outcomes) by the person-years at risk. Patients were observed from the fifth anniversary of the original diagnosis and censored at the time of outcome evaluation or at death. The post-5-year rate ratio (RR) for developing each late neurologic outcome, comparing survivors with siblings, was estimated by Poisson regression adjusted for age at the time of the study, sex, and race. Potential within-family correlation was accounted for by the generalized estimating equation. ${ }^{23}$ We considered the prevalence at the study entry for having developed each neurologic outcome in the first 5 years post diagnosis among the survivors. The same analysis of incidence rates as the post-5-year period is not applicable to the first 5 years because of the requirement of the 5-year survival for the CCSS cohort entry. The prevalence ratio at 5 years post ALL diagnosis was estimated by dividing the observed count of each outcome of the survivors by its expected count, assuming survivors had the same outcome rate as the age-sex-race-matched siblings. Siblings' hazard for developing each neurologic outcome was modeled by 5 -year age groups, sex, and race, which provided the rates for age-sex-race-matched siblings. The statistical inference of prevalence ratio was based on bootstrap, sampling families to account for potential within-family correlation. ${ }^{24}$

To evaluate effects of various factors, including age at diagnosis, therapy factors, relapse of the original cancer, and BMT, univariate and multivariate regressions were performed for each neurologic outcome, adjusting for age at the time of the study and sex. Decisions regarding which factors to include in the multivariate model were based on a priori anticipated clinical relevance and included factors not identified on the univariate analysis (Appendix Table A2, online only). Relapse from the original cancer and BMT were treated as time-dependent variables. All treatment exposures within 5 years from original diagnosis of ALL are considered. Starting at 5 years, cumulative incidence curves were calculated individually for auditory-vestibular-visual sensory deficits, focal neurologic dysfunction, seizure disorder, headache, or at least one neurologic deficit.

Multiple imputations under the assumption of "missing at random"25 were used to impute age at first occurrence of any neurologic outcome if a "yes" response was recorded without an age of first diagnosis. ${ }^{26}$ We used the multiple-imputation methodology of Taylor et $\mathrm{al}^{27}$ with slight modifications for event-time imputations. This method employs piece-wise exponential models to describe the rates of each neurologic outcome by age, age at diagnosis, sex, relapse occurrence, and treatments (cranial radiation and high-dose methotrexate). The model fitting used an expectation-maximization algorithm. The same multiple imputation strategy was used for handling siblings with missing age at first occurrence. This imputation was repeated 10 times creating 10 complete data sets without missing values of age. Each analysis was conducted 10 times using the 10 data sets, and the results were summarized by standard methods for combining multiple-imputation analyses. ${ }^{28}$ By repeating the imputation and analysis 10 times, we properly represent uncertainties of missing values in between-imputation variability.

\section{RESULTS}

\section{Study Population Characteristics}

General demographic information for patients and siblings in addition to basic treatment information for patients are included in Table 1. The median age at outcome assessment was 20.2 years (range, 5.9 to 44.6 years) for survivors and 26.4 years (range, 1.8 to 56.2 years) for siblings. The median follow-up time from ALL diagnosis to death or last survey was 14.1 years (range, 5.0 to 29.7 years). Siblings were on 


\begin{tabular}{|c|c|c|c|c|}
\hline \multirow[b]{2}{*}{ Characteristic } & \multicolumn{2}{|c|}{$\begin{array}{l}\text { Survivors } \\
(n=4,151)\end{array}$} & \multicolumn{2}{|c|}{$\begin{array}{c}\text { Siblings } \\
(\mathrm{n}=3,899)\end{array}$} \\
\hline & No. & $\%$ & No. & $\%$ \\
\hline \multicolumn{5}{|l|}{ Age at interview, years } \\
\hline$<20$ & 2,045 & 49.3 & 1,086 & 27.9 \\
\hline $20-29$ & 1,723 & 41.5 & 1,381 & 35.4 \\
\hline 30-39 & 372 & 9.0 & 1,116 & 28.6 \\
\hline $40+$ & 11 & 0.3 & 316 & 8.1 \\
\hline \multicolumn{5}{|l|}{ Sex } \\
\hline Male & 2,212 & 53.3 & 1,875 & 48.1 \\
\hline Female & 1,939 & 46.7 & 2,024 & 51.9 \\
\hline \multicolumn{5}{|l|}{ Race/ethnicity } \\
\hline White, non-Hispanic & 3,383 & 81.8 & 3,414 & 90.7 \\
\hline Black, non-Hispanic & 167 & 4.0 & 103 & 2.7 \\
\hline Hispanic/Latino & 260 & 6.3 & 138 & 3.7 \\
\hline Other & 327 & 7.9 & 107 & 2.8 \\
\hline \multicolumn{5}{|c|}{ Vital status at time of interview } \\
\hline Alive & 3,820 & 92.0 & & \\
\hline Dead & 331 & 8.0 & & \\
\hline \multicolumn{5}{|l|}{ Age at diagnosis, years } \\
\hline$<1$ & 56 & 1.3 & & \\
\hline $1-9$ & 3,340 & 80.5 & & \\
\hline $10+$ & 755 & 18.2 & & \\
\hline \multicolumn{5}{|l|}{ CNS therapy* } \\
\hline Cranial + IT & 2,220 & 60.8 & & \\
\hline Cranial XRT & 135 & 3.7 & & \\
\hline IT alone & 1,209 & 33.1 & & \\
\hline No cranial XRT or IT & 87 & 2.4 & & \\
\hline \multicolumn{5}{|l|}{ CNS therapy, Gy } \\
\hline Cranial $\geq 20$ & 1,281 & 35.1 & & \\
\hline Cranial $>0$ to $<20$ & 1,074 & 29.4 & & \\
\hline IT alone & 1,209 & 33.1 & & \\
\hline None & 87 & 2.4 & & \\
\hline \multicolumn{5}{|l|}{ MTX IV $†$} \\
\hline MTX IV, high dose & 422 & 11.5 & & \\
\hline MTX IV, not high dose & 956 & 26.1 & & \\
\hline No MTX or no MTX IV & 2,279 & 62.3 & & \\
\hline \multicolumn{5}{|l|}{ MTX IV (high dose)† } \\
\hline Yes & 422 & 11.5 & & \\
\hline No & 3,235 & 88.5 & & \\
\hline \multicolumn{5}{|l|}{ Recurrence } \\
\hline Yes & 846 & 20.4 & & \\
\hline No & 3,305 & 79.6 & & \\
\hline \multicolumn{5}{|l|}{ Bone marrow transplant } \\
\hline Yes & 208 & 5.1 & & \\
\hline No & 3,908 & 94.9 & & \\
\hline \multicolumn{5}{|c|}{$\begin{array}{l}\text { NOTE. Some variables had missing values (such as race and treatment data); } \\
\text { the numbers and percentages are based on available data only. } \\
\text { Abbreviations: IT, intrathecal; XRT, external radiation therapy; MTX, metho- } \\
\text { trexate; IV, intravenous. } \\
\text { "Cranial radiation includes a small number of patients ( } \mathrm{n}=342 \text { ) who were } \\
\text { treated with craniospinal radiation. The vast majority of patients who were } \\
\text { treated with cranial radiation were also treated with intrathecal therapy (only } \\
136 \text { of the patients treated with cranial radiation did not receive any intrathe- } \\
\text { cal therapy). } \\
+ \text { tHigh-dose methotrexate (IV) is defined as any dose of more than } \\
5,000 \mathrm{mg} / \mathrm{m}^{2} \text {. }\end{array}$} \\
\hline
\end{tabular}

average older than patients at the time of interview. A higher percentage of patients in the study group were male compared with the sibling group. There were more self-reported non-white survivors $(18.2 \%)$ compared with siblings (9.2\%).

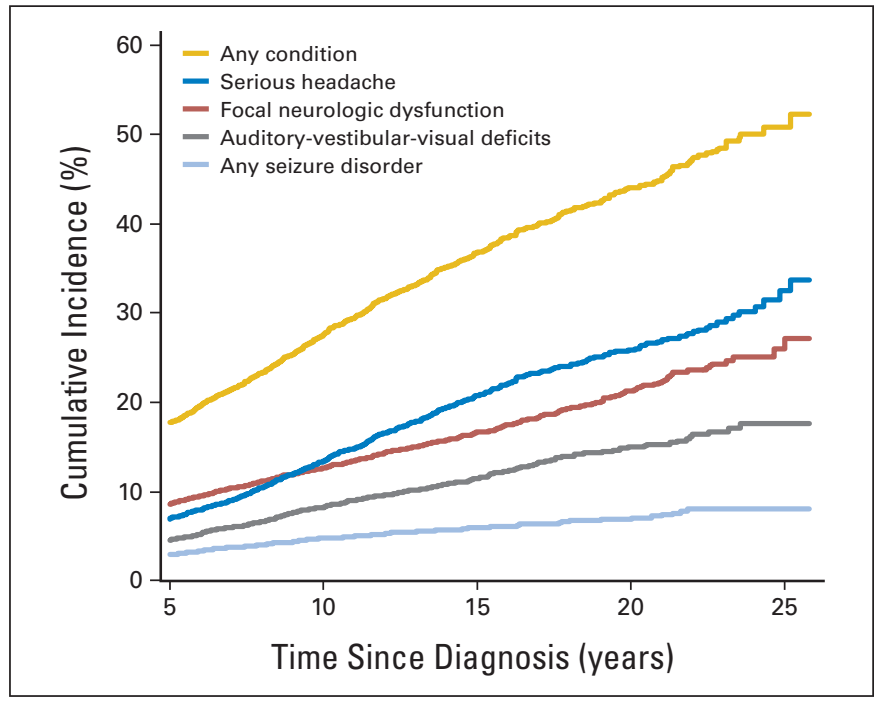

Fig 1. Cumulative incidence of selected chronic health conditions among 5-year survivors of acute lymphoblastic leukemia.

Approximately $80 \%$ of patients were between 1 and 9 years of age at diagnosis, and less than $2 \%$ were infants at diagnosis. The majority of patients $(64.5 \%)$ were treated with cranial radiation (median, 23.8 Gy; range, 1.5 to $74.4 \mathrm{~Gy}$ ). Of the patients who received cranial radiation, 67 received less than $17 \mathrm{~Gy}, 1,007$ had between $17 \mathrm{~Gy}$ and $20 \mathrm{~Gy}$, and 1,281 had more than $20 \mathrm{~Gy}$. Nearly all patients (94\%) received intrathecal therapy. Approximately $12 \%$ were treated with high-dose methotrexate $\left(\geq 5,000 \mathrm{mg} / \mathrm{m}^{2}\right)$. Twenty percent reported at least one recurrence of their ALL, and 5\% reported undergoing BMT. At the time of response, $92 \%$ of patients were alive and the other $8 \%$ had information reported by a proxy.

The overall cumulative incidence of any neurologic condition was $44.0 \%$ at 20 years (Fig 1). Serious headaches were most common, with a cumulative incidence of $25.8 \%$ at 20 years, followed by focal neurologic dysfunction (21.2\% at 20 years) and auditory-vestibularvisual sensory deficits ( $15.1 \%$ at 20 years). Reports of seizures had the lowest cumulative incidence of $7.0 \%$ at 20 years. The cumulative incidence of late neurologic conditions by age at diagnosis, sex, and exposure to cranial radiation is shown in Figure 2.

\section{Auditory-Vestibular-Visual Sensory Deficits: Hearing and Vision Problems}

A total of 445 auditory-vestibular-visual sensory deficits were reported (Table 2) by 333 patients. Of those, 289 (64.9\%) deficits developed late (at least 5 years after diagnosis). Late onset of persistent dizziness was more frequent (2.8 per 1,000 person-years) than other auditory-vestibular-visual sensory deficits. Relative to siblings, survivors were at elevated risk for all late-onset auditory-vestibular-visual sensory categories except any hearing impairment and legal blindness. Seventy-five survivors (26.5\%) reported two or more auditoryvestibular-visual sensory deficits (Table 3 ).

Univariate analysis (Appendix Table A2) and multivariable analysis (Table 4) revealed several factors that influenced risk of auditoryvestibular-visual sensory deficits after 5 years from diagnosis. Children 


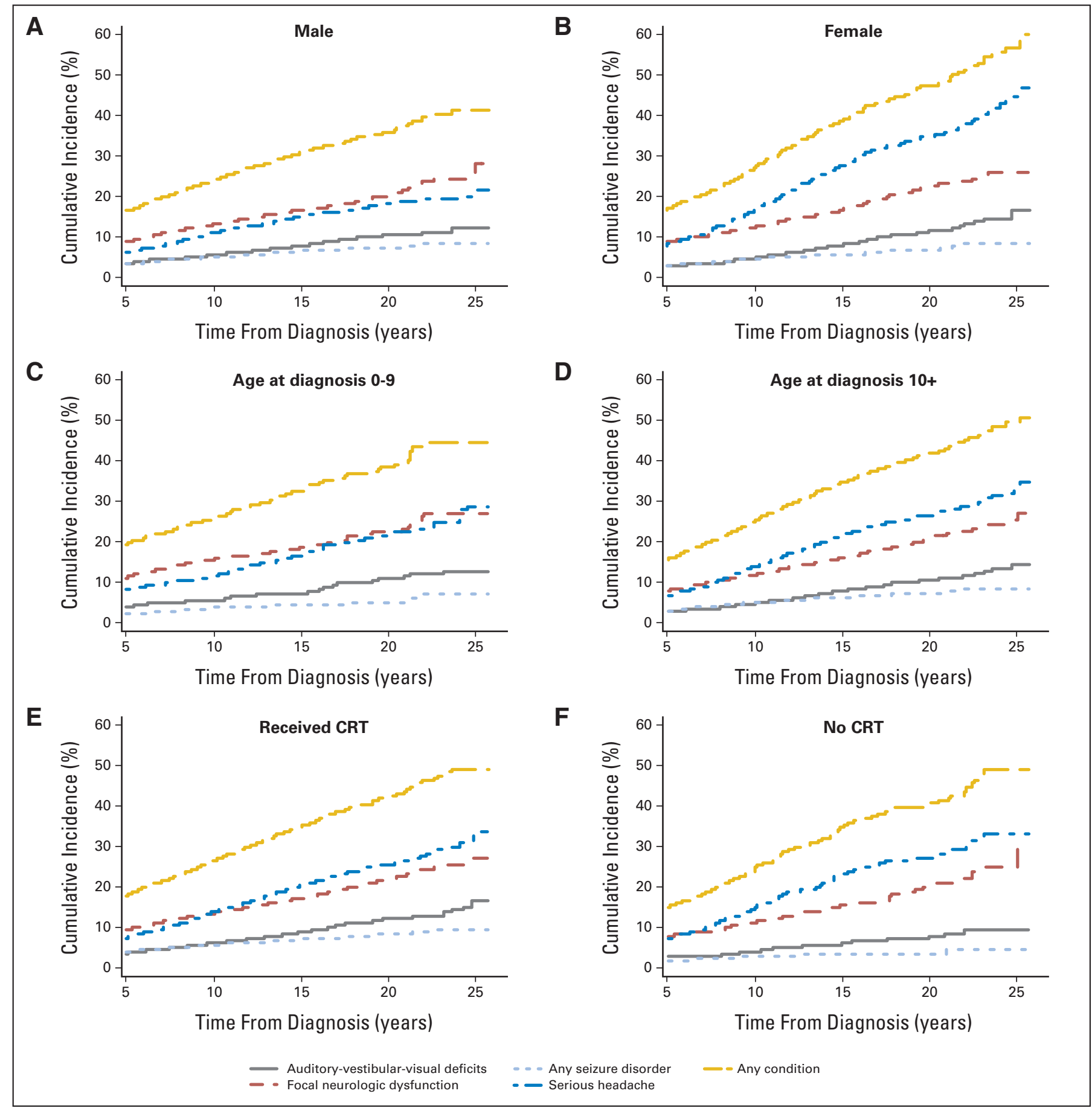

Fig 2. Cumulative incidence of selected neurologic conditions among 5 -year survivors of acute lymphoblastic leukemia by sex, age at diagnosis, and by cranial radiation therapy (CRT).

treated at 10 years of age or older had slightly lower risk of auditoryvestibular-visual sensory deficit compared with children treated between 1 and 9 years of age. Patients who relapsed (RR, 2.0; $P<.001)$ were at highest risk.

\section{Focal Neurologic Dysfunction: Motor and Coordination Problems}

Overall, 1,174 focal neurologic issues were reported (Table 2 ) by 696 patients. Of these, $626(53 \%)$ developed late $(>5$ years after diagnosis). Late coordination problems occurred at a rate of 4.1, motor problems at 3.3, decreased sensation at 3.0, and pain sensation at 6.1 per 1,000 patient-years. Relative to siblings, patients were at elevated risk for late-onset coordination problems (RR, $4.1 ; P<.001)$, motor problems (RR, 5.0; $P<.001$ ), decreased sensation (RR, 2.3; $P<.001)$ and pain sensation (RR, 3.0; $P<.001)$. Also, 151 survivors $(30.2 \%)$ reported two or more focal neurologic conditions (Table 3 ). Patients who relapsed had increased risk for developing late focal neurologic problems (RR, 2.2; $P<.001)$. 


\begin{tabular}{|c|c|c|c|c|c|c|c|c|c|c|c|}
\hline \multirow[b]{3}{*}{ Conditions } & \multicolumn{5}{|c|}{ Auditory-Vestibular-Visual Sensory Deficits } & \multicolumn{4}{|c|}{ Focal Neurologic Dysfunction } & \multirow[b]{2}{*}{$\begin{array}{l}\text { Any Seizure } \\
\text { Disorder }\end{array}$} & \multirow[b]{2}{*}{$\begin{array}{c}\text { Any } \\
\text { Headache }\end{array}$} \\
\hline & $\begin{array}{l}\text { Any Hearing } \\
\text { Impairment }\end{array}$ & Tinnitus & $\begin{array}{l}\text { Persistent } \\
\text { Dizziness }\end{array}$ & $\begin{array}{c}\text { Legal } \\
\text { Blindness in } \\
\text { One or Both } \\
\text { Eyes }\end{array}$ & $\begin{array}{l}\text { Double } \\
\text { Vision }\end{array}$ & $\begin{array}{c}\text { Any } \\
\text { Coordination } \\
\text { Problem } \\
\end{array}$ & $\begin{array}{l}\text { Any Motor } \\
\text { Problem }\end{array}$ & $\begin{array}{l}\text { Decreased } \\
\text { Touch or } \\
\text { Feeling }\end{array}$ & $\begin{array}{l}\text { Pain or } \\
\text { Abnormal } \\
\text { Sensation }\end{array}$ & & \\
\hline & No. $\%$ & No. $\%$ & No. & No. $\%$ & No. & No. $\%$ & No. & No. & No. & No. & No. \\
\hline \multicolumn{12}{|l|}{ Reported outcome } \\
\hline Yes* & $56 \quad 1.4$ & $136 \quad 3.3$ & $141 \quad 3.4$ & 1.1 & $66 \quad 1.6$ & $306 \quad 7.5$ & $268 \quad 6.5$ & 215 & 385 & 249 & $848 \quad 20.8$ \\
\hline Not & $4,065 \quad 98.6$ & $3,995 \quad 96.7$ & $4,003 \quad 96.6$ & $4,093 \quad 98.9$ & $4,076 \quad 98.4$ & $3,796 \quad 92.5$ & $3,830 \quad 93.5$ & $3,915 \quad 94.8$ & $3,705 \quad 90.6$ & $3,860 \quad 93.9$ & 3,232 \\
\hline \multicolumn{12}{|c|}{ Diagnosis to 5 years } \\
\hline Yes & 36 & 37 & 29 & 23 & 31 & 149 & 142 & 100 & 157 & 123 & 286 \\
\hline PR $\neq$ & 4.1 & 1.8 & 3.1 & 2.3 & 5.4 & 9.9 & 19.0 & 16.7 & 11.8 & 7.5 & 2.3 \\
\hline $95 \% \mathrm{Cl}$ & 2.6 to 6.7 & 1.2 to 2.8 & 1.9 to 5.2 & 1.3 to 4.3 & 2.8 to 10.1 & 7.1 to 13.8 & 11.8 to 30.5 & 11.1 to 24.9 & 8.6 to 16.1 & 5.4 to 10.2 & 2.0 to 2.7 \\
\hline$P$ & $<.001$ & .008 & $<.001$ & .006 & $<.001$ & $<.001$ & $<.001$ & $<.001$ & $<.001$ & $<.001$ & $<.001$ \\
\hline \multicolumn{12}{|c|}{5 years after diagnosis } \\
\hline Yes* & 20 & 99 & 112 & 23 & 35 & 157 & 126 & 115 & 228 & 126 & 562 \\
\hline Rate§ & 0.5 & 2.5 & 2.8 & 0.6 & 0.9 & 4.1 & 3.3 & 3.0 & 6.1 & 3.3 & 16.2 \\
\hline $95 \% \mathrm{Cl}$ & 0.5 to 0.6 & 2.4 to 2.7 & 2.8 to 2.9 & 0.5 to 0.6 & 0.8 to 1.0 & 3.9 to 4.3 & 3.1 to 3.5 & 2.8 to 3.1 & 5.9 to 6.3 & 3.1 to 3.4 & 15.8 to 16.6 \\
\hline RRI & 1.9 & 1.6 & 2.7 & 1.6 & 2.5 & 4.1 & 5.0 & 2.3 & 3.0 & 4.6 & 1.6 \\
\hline $95 \% \mathrm{Cl}$ & 1.1 to 3.3 & 1.2 to 2.1 & 2.1 to 3.6 & 0.9 to 2.8 & 1.5 to 4.0 & 3.1 to 5.3 & 3.8 to 6.7 & 1.8 to 2.9 & 2.5 to 3.7 & 3.4 to 6.2 & 1.4 to 1.7 \\
\hline$P$ & .026 & $<.001$ & $<.001$ & .107 & $<.001$ & $<.001$ & $<.001$ & $<.001$ & $<.001$ & $<.001$ & $<.001$ \\
\hline \multicolumn{12}{|c|}{$\begin{array}{l}\text { Abbreviations: RR, rate ratio; PR, prevalence ratio. } \\
\text { "Excludes conditions prior to diagnosis. } \\
\text { tIncludes "not sure" and missing responses. } \\
\text { †PR at cohort entry ( } 5 \text { years since acute lymphoblastic leukemia diagnosis), adjusted for age, sex, and race; relative to siblings. } \\
\text { §Rate per } 1,000 \text { person-years. } \\
\text { १RR, adjusted for age, sex, and race; relative to siblings; } P \leq .001 \text {. }\end{array}$} \\
\hline
\end{tabular}

\section{Seizures}

A total of 249 patients (6.1\%) reported a seizure disorder (Table 2 ). Seizures were a late-onset problem in $51 \%$ of patients. Survivors were at increased risk for developing a late seizure disorder when compared with siblings (RR, 4.6; $P<.001$ ). Patients who relapsed were also at higher risk for developing late-onset seizures (RR, 2.6; $P=.002)$.

\section{Headaches}

Headaches were the most commonly reported neurologic issue, with a total of $848(21 \%)$ survivors experiencing severe headaches.
Most (66\%) reported late onset. The risk of developing late-onset headaches was increased in the patient group compared with the sibling group $(\mathrm{RR}, 1.6 ; P<.001)$. Male survivors were at lower risk (RR, $0.4 ; P<.001$ ) compared with female survivors. Older age at diagnosis (10 years of age or older) decreased the risk of late-onset headaches $(\mathrm{RR}, 0.6 ; P<.001)$.

\section{Multiple Neurologic Conditions}

To assess whether findings were driven by a smaller group of survivors with multiple abnormalities or a larger group with only one abnormality, we evaluated how many survivors reported two or more

\begin{tabular}{|c|c|c|c|c|c|c|c|c|c|c|c|c|}
\hline Condition & No. & $\%$ & No. & $\%$ & No. & $\%$ & No. & $\%$ & No. & $\%$ & No. & $\%$ \\
\hline \multicolumn{13}{|l|}{ Reported outcome } \\
\hline Yes* & 333 & 8.2 & 93 & 2.3 & 696 & 17.4 & 290 & 7.2 & 1,395 & 35.7 & 448 & 11.6 \\
\hline Yes* & 208 & & \multicolumn{2}{|l|}{75} & \multicolumn{2}{|l|}{348} & \multicolumn{2}{|l|}{151} & \multicolumn{2}{|l|}{919} & \multicolumn{2}{|l|}{190} \\
\hline Rateł & \multicolumn{2}{|c|}{5.5} & \multirow{2}{*}{\multicolumn{2}{|c|}{$\begin{array}{c}1.9 \\
1.9 \text { to } 2.0\end{array}$}} & \multicolumn{2}{|c|}{10.0} & \multicolumn{2}{|c|}{4.2} & \multicolumn{2}{|c|}{28.7} & \multicolumn{2}{|c|}{6.6} \\
\hline $95 \% \mathrm{Cl}$ & \multicolumn{2}{|c|}{5.3 to 5.8} & & & \multicolumn{2}{|c|}{9.6 to 10.5} & \multicolumn{2}{|c|}{4.2 to 4.3} & \multicolumn{2}{|c|}{28.2 to 29.3} & \multicolumn{2}{|c|}{6.2 to 7.0} \\
\hline $\mathrm{RR} \S$ & \multicolumn{2}{|c|}{1.8} & \multicolumn{2}{|c|}{8.0} & & & 4 & & & & & \\
\hline $95 \% \mathrm{Cl}$ & \multicolumn{2}{|c|}{1.5 to 2.2} & \multicolumn{2}{|c|}{5.1 to 12.7} & \multicolumn{2}{|c|}{2.5 to 3.3} & \multicolumn{2}{|c|}{3.7 to 6.5} & \multicolumn{2}{|c|}{2.2 to 2.6} & \multicolumn{2}{|c|}{1.6 to 2.3} \\
\hline
\end{tabular}




\begin{tabular}{|c|c|c|c|c|c|c|c|c|c|c|c|c|}
\hline & \multicolumn{3}{|c|}{$\begin{array}{c}\text { Auditory-Vestibular-Visual } \\
\text { Sensory Deficits }\end{array}$} & \multicolumn{3}{|c|}{ Focal Neurologic Dysfunction } & \multicolumn{3}{|c|}{ Any Seizure Disorder } & \multicolumn{3}{|c|}{ Any Headache } \\
\hline & $\mathrm{RR}$ & $95 \% \mathrm{Cl}$ & $P$ & RR & $95 \% \mathrm{Cl}$ & $P$ & RR & $95 \% \mathrm{Cl}$ & $P$ & $\mathrm{RR}$ & $95 \% \mathrm{Cl}$ & $P$ \\
\hline \multicolumn{13}{|c|}{ Age at diagnosis, years } \\
\hline$<1$ & 0.5 & 0.1 to 3.7 & .74 & 0.7 & 0.2 to 2.8 & .63 & 0.9 & 0.1 to 6.9 & .96 & 1.3 & 0.6 to 2.7 & .45 \\
\hline $10+$ & 0.8 & 0.5 to 1.3 & .38 & 1.0 & 0.7 to 1.4 & .95 & 0.7 & 0.4 to 1.2 & .19 & 0.6 & 0.4 to 0.8 & $<.001$ \\
\hline 1-9 (referent) & 1.0 & & & 1.0 & & & 1.0 & & & 1.0 & & \\
\hline \multicolumn{13}{|l|}{ Sex } \\
\hline Male & 0.8 & 0.6 to 1.1 & .19 & 1.0 & 0.8 to 1.2 & .76 & 1.2 & 0.8 to 1.8 & .44 & 0.4 & 0.3 to 0.5 & $<.001$ \\
\hline Female (referent) & 1.0 & & & 1.0 & & & 1.0 & & & 1.0 & & \\
\hline \multicolumn{13}{|l|}{ Cranial radiation } \\
\hline$\geq 20 \mathrm{~Gy}$ & 1.4 & 0.9 to 2.2 & .09 & 1.1 & 0.8 to 1.5 & .40 & 1.3 & 0.8 to 2.2 & .33 & 0.9 & 0.7 to 1.1 & .31 \\
\hline$<20 \mathrm{~Gy}$ & 1.5 & 0.9 to 2.4 & .08 & 1.0 & 0.7 to 1.4 & .81 & 0.9 & 0.5 to 1.7 & .75 & 1.0 & 0.8 to 1.3 & .97 \\
\hline None & 0.5 & 0.1 to 2.4 & .35 & 1.3 & 0.7 to 2.6 & .43 & 0.5 & 0.1 to 3.4 & .44 & 0.5 & 0.2 to 1.2 & .13 \\
\hline IT alone (referent) & 1.0 & & & 1.0 & & & 1.0 & & & 1.0 & & \\
\hline \multicolumn{13}{|l|}{ MTX IV (high dose) } \\
\hline Yes & 1.5 & 0.9 to 2.7 & .12 & 1.1 & 0.7 to 1.7 & .75 & 0.9 & 0.4 to 2.0 & .74 & 1.0 & 0.7 to 1.4 & .88 \\
\hline No (referent) & 1.0 & & & 1.0 & & & 1.0 & & & 1.0 & & \\
\hline \multicolumn{13}{|l|}{ Recurrence } \\
\hline Yes & 2.0 & 1.4 to 2.9 & $<.001$ & 2.2 & 1.7 to 3.0 & $<.001$ & 2.5 & 1.5 to 4.2 & $<.001$ & 1.2 & 0.9 to 1.6 & .13 \\
\hline No (referent) & 1.0 & & & 1.0 & & & 1.0 & & & 1.0 & & \\
\hline \multicolumn{13}{|c|}{ Bone marrow transplant } \\
\hline Yes & 1.2 & 0.5 to 2.8 & .69 & 1.1 & 0.6 to 2.2 & .79 & 1.2 & 0.4 to 3.4 & .76 & 0.6 & 0.3 to 1.4 & .26 \\
\hline No (referent) & 1.0 & & & 1.0 & & & 1.0 & & & 1.0 & & \\
\hline
\end{tabular}

Abbreviations: RR, rate ratio; IT, intrathecal; MTX, methotrexate; IV, intravenous.

neurologic conditions. The majority $(82.9 \%)$ reported only one of the four neurologic problems (Table 3).

\section{DISCUSSION}

CNS-directed therapy is a key contributing factor to improving survival among children with ALL. When cranial radiation was linked to neurocognitive deficits, therapeutic regimens were modified to reduce or eliminate cranial radiation by substituting intensified intrathecal and systemic chemotherapy. ${ }^{29,30}$ These CNS-directed therapies could also influence risk of late neurologic outcomes. We found that the risk of developing late neurologic complications is higher for survivors who received cranial radiation and/or suffered relapse of their leukemia.

Acute neurologic effects of direct leukemic CNS involvement and treatment-related complications are relatively well known. ${ }^{31} \mathrm{CNS}$ imaging changes on computed tomography and magnetic resonance imaging have been identified in ALL patients during and after therapy. ${ }^{32,33}$ Whether systemic therapies and/or aggressive intrathecal therapies with known acute neurologic toxicities can lead to delayed neurologic consequences is unknown. In this cohort, systemic therapies and/or intrathecal therapies did not seem to influence risk of reported late neurologic complications.

Radiation to the CNS can injure the supportive tissues and neurogenic microenvironment of the nervous system and lead to neuronal loss or damage. Oxygen-free-radical damage and altered cytokine responses may influence the development of late delayed damage. ${ }^{34}$ Glial and neuronal stem-cell damage may result in a progressive demyelination and/or neuronal cell loss. As patients age, endothelial damage may lead to vascular anomalies, including telangiectasias or malformations. ${ }^{35}$ Radiation-induced genetic changes can lead to late development of second neoplasms. ${ }^{36}$ Radiation can also increase the risk of stroke in this patient population but stroke usually occurs in patients who received $30 \mathrm{~Gy}$ or more of cranial radiation. ${ }^{37}$ These late effects of cranial radiation may predispose patients to developing late neurologic consequences.

While neurocognitive, neuropathologic, and behavioral consequences of childhood cancer therapy have been well documented, ${ }^{9}$ there are limited data on other neurologic complications, such as motor and coordination dysfunction, sensory loss, seizures, and headaches. In one study of 40 children with ALL, 23\% were found to have neurologic signs at diagnosis, 30\% developed gross motor disturbances and $18 \%$ developed fine motor dysfunction. ${ }^{38}$ Motor dysfunction can persist for years after therapy, manifesting as difficulty with fine motor and handwriting skills. ${ }^{39}$ Strength, balance, and agility can be reduced after ALL therapy compared with that in age-matched controls. ${ }^{40}$ These findings are consistent with the reported $21.2 \%$ cumulative incidence of focal neurologic dysfunction in ALL survivors of the CCSS cohort.

There are fewer reports on auditory-vestibular-visual sensory complications and seizures after ALL therapy. Ocular morbidity and vision disturbance have rarely been reported in survivors of ALL. ${ }^{41,42}$ Hearing loss occurs as a consequence of the leukemia, cancer therapy, or ototoxic supportive therapy. There are no long-term follow-up studies on hearing-related issues in ALL survivors. In one study, ${ }^{43}$ reduced performance on simple alerted auditory reaction time was found in children, and it correlated with cortical atrophy and calcifications. Approximately $10 \%$ of patients will have a seizure during therapy. ${ }^{11,44}$ We found the cumulative 20 -year incidence of auditoryvestibular-visual sensory deficits to be $15.1 \%$ and $7 \%$ for seizures. 
We identified serious headaches as the most common selfreported late neurologic condition. In both siblings and survivors, headaches were more common in females. Headaches were twice as common in both male and female survivors before age 20 but not different later in life (data not shown).

Patients who relapsed and/or those treated with BMT were at highest risk for neurologic sequelae. Relapse can occur in the CNS and increase the risk of neurologic complications. The data regarding site of relapse were not captured; thus, we are unable to determine the influence on risk of CNS involvement at relapse. Relapsed ALL generally requires more intensive therapy and consideration of BMT.

The large size of this cohort and the quality of the data are strengths of this study; however, certain limitations are recognized. First, CNS disease status at diagnosis was not recorded. Second, occurrence and time of onset of sequelae were obtained by self-report. There is a possibility that patients may report a deficit as a new problem 5 years after diagnosis and treatment when it was actually present earlier. We relied on the time at which the condition was diagnosed or confirmed by a physician. Third, self-reported events and response bias can lead to underestimation of problems by denial of difficulties in the survivor population. ${ }^{45}$ Additionally, we do not have the ability to assess the validity of the various outcomes included in the analysis, irrespective of whether the respondent was the survivor or a proxy. While CCSS investigators have had excellent success in validating selected outcomes, such as second malignancies, our success in achieving medical record validation for other major outcomes has been limited. ${ }^{46}$ Previous reports have demonstrated that survivors of stemcell transplantation have the ability to recall many outcomes with a relatively good level of sensitivity and specificity, ${ }^{47}$ but this does not address the issue of proxy reports or level of neurocognitive functioning that may apply to the childhood ALL population. Finally, it is possible that some reported late effects could be related to progressive disease because patients who were alive but had active disease at the 5-year follow-up points were eligible patients. Although this was likely a small number of patients, the methods of data capture do not allow separate analysis of disease state at time of entry.

While there is increased risk of late neurologic consequences in adult survivors of ALL, especially those treated with cranial radiation, many are free of reported problems. Substantial efforts to limit cranial radiation have been instituted since the era reflected in this study. It will be important to see if the risks of late neurologic consequences change as therapy continues to evolve.

\section{AUTHORS' DISCLOSURES OF POTENTIAL CONFLICTS OF INTEREST}

The author(s) indicated no potential conflicts of interest.

\section{AUTHOR CONTRIBUTIONS}

Conception and design: Robert E. Goldsby, Lonnie Zeltzer, Leslie L.

Robison, Roger J. Packer

Financial support: Robert E. Goldsby, Leslie L. Robison

Administrative support: Robert E. Goldsby, Shannon H. Raber, Daniel

Hill, Gregory T. Armstrong, Leslie L. Robison

Provision of study materials or patients: Lonnie Zeltzer,

Leslie L. Robison

Collection and assembly of data: Robert E. Goldsby, Leslie L. Robison

Data analysis and interpretation: Robert E. Goldsby, Qi Liu, Daniel C.

Bowers, Amanda Yeaton-Massey, Shannon H. Raber, Daniel Hill, Yutaka

Yasui, Lonnie Zeltzer, Leslie L. Robison, Roger J. Packer

Manuscript writing: Robert E. Goldsby, Paul C. Nathan, Amanda

Yeaton-Massey, Shannon H. Raber, Daniel Hill, Yutaka Yasui, Lonnie

Zeltzer, Leslie L. Robison, Roger J. Packer

Final approval of manuscript: Robert E. Goldsby, Paul C. Nathan, Daniel C. Bowers, Gregory T. Armstrong, Yutaka Yasui, Lonnie Zeltzer, Leslie L. Robison, Roger J. Packer

\section{REFERENCES}

1. Pui $\mathrm{CH}$, Robison LL, Look AT: Acute lymphoblastic leukaemia. Lancet 371:1030-1043, 2008

2. Rivera GK, Pinkel D, Simone JV, et al: Treatment of acute lymphoblastic leukemia: 30 years' experience at St. Jude Children's Research Hospital. N Engl J Med 329:1289-1295, 1993

3. Cousens P, Waters B, Said J, et al: Cognitive effects of cranial irradiation in leukaemia: A survey and meta-analysis. J Child Psychol Psychiatry 29: 839-852, 1988

4. Meadows AT, Gordon J, Massari DJ, et al: Declines in $\mathrm{IQ}$ scores and cognitive dysfunctions in children with acute lymphocytic leukaemia treated with cranial irradiation. Lancet 2:1015-1018, 1981

5. Kuskonmaz B, Unal S, Gumruk F, et al: The neurologic complications in pediatric acute lymphoblastic leukemia patients excluding leukemic infiltration. Leuk Res 30:537-541, 2006

6. Mahoney DH Jr, Shuster JJ, Nitschke R, et al: Acute neurotoxicity in children with B-precursor acute lymphoid leukemia: An association with intermediate-dose intravenous methotrexate and intrathecal triple therapy-a Pediatric Oncology Group study. J Clin Oncol 16:1712-1722, 1998

7. Lo Nigro L, Di Cataldo A, Schiliro G: Acute neurotoxicity in children with B-lineage acute lymphoblastic leukemia (B-ALL) treated with intermedi- ate risk protocols. Med Pediatr Oncol 35:449-455, 2000

8. Atra A, Pinkerton CR, Bouffet $E$, et al: Acute neurotoxicity in children with advanced stage B-nonHodgkin's lymphoma and B-acute lymphoblastic leukaemia treated with the United Kingdom children cancer study group 9002/9003 protocols. Eur J Cancer 40:1346-1350, 2004

9. Nathan PC, Patel SK, Dilley K, et al: Guidelines for identification of, advocacy for, and intervention in neurocognitive problems in survivors of childhood cancer: A report from the Children's Oncology Group. Arch Pediatr Adolesc Med 161:798-806, 2007

10. Moleski M: Neuropsychological, neuroanatomical, and neurophysiological consequences of CNS chemotherapy for acute lymphoblastic leukemia. Arch Clin Neuropsychol 15:603-630, 2000

11. Maytal J, Grossman R, Yusuf FH, et al: Prognosis and treatment of seizures in children with acute lymphoblastic leukemia. Epilepsia 36:831-836, 1995

12. Gay CT, Bodensteiner JB, Nitschke $R$, et al: Reversible treatment-related leukoencephalopathy. J Child Neurol 4:208-213, 1989

13. Chessells JM, Cox TC, Kendall B, et al: Neurotoxicity in lymphoblastic leukaemia: Comparison of oral and intramuscular methotrexate and two doses of radiation. Arch Dis Child 65:416-422, 1990
14. Moore IM, Kramer JH, Wara W, et al: Cognitive function in children with leukemia. Effect of radiation dose and time since irradiation. Cancer 68:1913-1917, 1991

15. Mulhern RK, Fairclough D, Ochs J: A prospective comparison of neuropsychologic performance of children surviving leukemia who received 18-Gy, 24-Gy, or no cranial irradiation. J Clin Oncol 9:13481356, 1991

16. Waber DP, Tarbell NJ, Kahn CM, et al: The relationship of sex and treatment modality to neuropsychologic outcome in childhood acute lymphoblastic leukemia. J Clin Oncol 10:810-817, 1992

17. Jannoun L: Are cognitive and educational development affected by age at which prophylactic therapy is given in acute lymphoblastic leukaemia? Arch Dis Child 58:953-958, 1983

18. Lansky SB, Cairns NU, Lansky LL, et al: Central nervous system prophylaxis. Studies showing impairment in verbal skills and academic achievement. Am J Pediatr Hematol Oncol 6:183190, 1984

19. Robison LL, Nesbit ME Jr, Sather HN, et al: Factors associated with 10 scores in long-term survivors of childhood acute lymphoblastic leukemia. Am J Pediatr Hematol Oncol 6:115-121, 1984

20. Robison LL, Green DM, Hudson M, et al: Long-term outcomes of adult survivors of childhood cancer. Cancer 104:2557-2564, 2005 
21. Robison LL, Mertens AC, Boice JD, et al: Study design and cohort characteristics of the Childhood Cancer Survivor Study: A multi-institutiona collaborative project. Med Pediatr Oncol 38:229239, 2002

22. Mertens AC, Walls RS, Taylor $L$, et al: Characteristics of childhood cancer survivors predicted their successful tracing. J Clin Epidemiol 57:933 944, 2004

23. Zeger $S L$, Liang $K Y$ : Longitudinal data analysis for discrete and continuous outcomes. Biometrics 42:121-130, 1986

24. Efron B, Tibshirani R: An Introduction to the Bootstrap. New York, NY, Chapman and Hall, 1993

25. Little RJA, Rubin DB: Statistical Analysis With Missing Data (ed 2). New York, NY, John Wiley \& Sons, 2002

26. Rubin D: Multiple Imputation for Nonresponse in Surveys. New York, NY, John Wiley \& Sons, 1987

27. Taylor JM, Munoz A, Bass SM, et al: Estimating the distribution of times from HIV seroconversion to AIDS using multiple imputation. Multicentre AIDS Cohort Study. Stat Med 9:505-514, 1990

28. Little RJA, Rubin DB: Statistical Analysis with Missing Data. New York, NY, John Wiley \& Sons, 1987

29. Pullen J, Boyett J, Shuster J, et al: Extended triple intrathecal chemotherapy trial for prevention of CNS relapse in good-risk and poor-risk patients with B-progenitor acute lymphoblastic leukemia: A Pediatric Oncology Group study. J Clin Oncol 11: 839-849, 1993

30. Bleyer WA, Poplack DG: Prophylaxis and treatment of leukemia in the central nervous system and other sanctuaries. Semin Oncol 12:131-148, 1985

31. Chamberlain $M$ : Neurologic complications of leukemia, in Schiff D, Kesari S, Wen P (eds): Cancer Neurology in Clinical Practice (ed 2). Totowa, NJ, Humana Press, 2008, pp 555-565

32. Chen $C Y$, Zimmerman RA, Faro $S$, et al: Childhood leukemia: Central nervous system abnor malities during and after treatment. AJNR Am J Neuroradiol 17:295-310, 1996

33. Hertzberg $H$, Huk WJ, Ueberall MA, et al: CNS late effects after ALL therapy in childhood. Part I: Neuroradiological findings in long-term survivors of childhood ALL-An evaluation of the interferences between morphology and neuropsychological performance. The German Late Effects Working Group. Med Pediatr Oncol 28:387-400, 1997

34. Kim JH, Brown SL, Jenrow KA, et al: Mechanisms of radiation-induced brain toxicity and implications for future clinical trials. J Neurooncol 87:279-286, 2008

35. Larson JJ, Ball WS, Bove KE, et al: Formation of intracerebral cavernous malformations after radiation treatment for central nervous system neoplasia in children. J Neurosurg 88:51-56, 1998

36. Gold DG, Neglia JP, Dusenbery KE: Second neoplasms after megavoltage radiation for pediatric tumors. Cancer 97:2588-2596, 2003

37. Bowers DC, Liu Y, Leisenring $W$, et al: Lateoccurring stroke among long-term survivors of childhood leukemia and brain tumors: A report from the Childhood Cancer Survivor Study. J Clin Oncol 24: 5277-5282, 2006

38. Vainionpää L: Clinical neurological findings of children with acute lymphoblastic leukaemia at diag- nosis and during treatment. Eur J Pediatr 152:115119,1993

39. Reinders-Messelink HA, Schoemaker MM Hofte $M$, et al: Fine motor and handwriting problems after treatment for childhood acute lymphoblastic leukemia. Med Pediatr Oncol 27:551-555, 1996

40. Wright MJ, Halton JM, Martin RF, et al: Long-term gross motor performance following treatment for acute lymphoblastic leukemia. Med Pediatr Oncol 31:86-90, 1998

41. Hoover DL, Smith LE, Turner SJ, et al: Ophthalmic evaluation of survivors of acute lymphoblastic leukemia. Ophthalmology 95:151-155, 1988

42. Weaver RG Jr, Chauvenet $A R$, Smith $T J$, Schwartz AC: Ophthalmic evaluation of long-term survivors of childhood acute lymphoblastic leukemia. Cancer 58:963-968, 1986

43. Brouwers $P$, Riccardi $R$, Poplack $D$, et al: Attentional deficits in long-term survivors of childhood acute lymphoblastic leukemia (ALL). J Clin Neuropsychol 6:325-336, 1984

44. Ochs JJ, Bowman WP, Pui CH, et al: Seizures in childhood lymphoblastic leukaemia patients. Lancet 2:1422-1424, 1984

45. O'Leary TE, Diller L, Recklitis CJ: The effects of response bias on self-reported quality of life among childhood cancer survivors. Qual Life Res 16:1211-1220, 2007

46. Leisenring WM, Mertens AC, Armstrong GT et al: Pediatric cancer survivorship research: Experience of the Childhood Cancer Survivor Study. J Clin Oncol 27:2319-2327, 2009

47. Louie AD, Robison LL, Bogue $M$, et al: Validation of self-reported complications by bone marrow transplantation survivors. Bone Marrow Transplant 25:1191-1196, 2000 